\title{
Variação da ecogenicidade difusa em parênquima hepático homogêneo relacionada aos achados bioquímicos e hematológicos em cães ${ }^{1}$
}

\author{
Fernanda P. Medeiros ${ }^{2 *}$, Douglas A. de Freitas ${ }^{3}$ e Júlio C. Canola ${ }^{4}$
}

\begin{abstract}
Medeiros F.P., Freitas D.A. \& Canola J.C. 2013. [Diffuse echogenicity variation in homogeneous liver parenchyma related to biochemical and hematological findings in dogs.] Variação da ecogenicidade difusa em parênquima hepático homogêneo relacionada aos achados bioquímicos e hematológicos em cães. Pesquisa Veterinária Brasileira 33(Supl.1):85-92. Departamento de Cirurgia Veterinária, Faculdade de Ciências Agrárias e Veterinárias, Universidade Estadual Paulista Júlio de Mesquita Filho, Campus de Jaboticabal, SP 14884-900, Brazil. E-mail: femedeiros_vet@yahoo.com.br

The present study evaluated the liver with homogeneous parenchyma in dogs, with diffuse reduced echogenicity (G1), increased echogenicity (G2) and normal echogenicity (G3) by ultrasound examination associating the findings on animal profile, liver size and hematology and biochemistry results. Blood samples obtained by cephalic or jugular venipunture were submitted for hemogram and ALT, ALP, total proteins, albumin, globulin, urea and creatinine analysis. Among the 30 dogs in G1, 30 (100\%) presented portal venous and gall bladder wall clarity, 23 (76.67\%) presented normal liver size and edges, $15(50 \%)$ were from 1 to 6 years old and $8(26.67 \%)$ belonged to the lhasa apso breed. No predispositions were found according to gender, as well as no significant alterations in biochemical and hematological exams were observed in G1. The most prevalent disease found in this group was gastroenteritis (43.33\%). Among the 30 dogs in G2, 27 $(90 \%)$ presented hepatomegaly and rounded hepatic edges, 18 (60\%) were over 9 years old, 16 $(53.33 \%)$ were female and $9(30 \%)$ belonged to the poodle breed. The laboratorial findings related to this group were increased ALT and ALP serum activity, decreased levels of total protein, albumin, globulin, erythrocytes and hematocrit, as well as leukocytosis with neutrophilia and a left shift, eosinopenia, lymphopenia and monocytosis. The most prevalent diseases found in this group were metabolic disorders (54\%), such as diabetes mellitus and hyperadrenocorticism, and chronic hepatopathies (17\%) due to prolonged and continuous use of corticoid and anticonvulsive drugs. Among the 30 dogs in the control group (G3), normal liver size and edges were presented in $22(73.33 \%)$. In this group, no alterations were seen in laboratorial exams.
\end{abstract}

INDEX TERMS: Liver, ultrasound, hematology, biochemistry, dogs.

\footnotetext{
${ }^{1}$ Recebido em 21 de novembro de 2013.

Aceito para publicação em 2 de dezembro de 2013.

${ }^{2}$ Doutoranda do Departamento de Cirurgia Veterinária (subárea Diagnóstico por Imagem), Faculdade de Ciências Agrárias e Veterinárias (FCAV), Universidade Estadual Paulista Júlio de Mesquita Filho (Unesp), Via de Acesso Prof. Paulo Donato Castellane s/n, Jaboticabal, SP 14884900, Brasil. Endereço particular: Rua Mário Carpenter 22, apto 42, Gonzaga, Santos, SP 11055-260, Brasil. *Autor para correspondência: femedeiros_vet@yahoo.com.br

${ }^{3}$ Médico Veterinário, Sócio proprietário do Laboratório de Análises Clínicas CITOVET Ltda, Rua Sena Madureira, 898, Vila Clementino, São Paulo, SP 04021-001, Brasil.

${ }^{4}$ Departamento de Clínica e Cirurgia Veterinária, FCAV-Unesp, Via de Acesso Prof. Paulo Donato Castellane s/n, Jaboticabal, SP 14884-900. E-mail: canola@fcav.unesp.br
}

RESUMO.- No presente estudo foi analisado o parênquima hepático com características homogêneas e ecogenicidade difusa reduzida (G1), aumentada (G2) e normal (G3), em relação ao perfil dos animais, dimensão do fígado e achado bioquímico e hematológico. Amostras de sangue obtidas por punção venosa da jugular ou da cefálica do antebraço foram encaminhadas para realização de hemograma e dosagem sérica de ALT, FA, proteínas totais, albumina, globulina, uréia e creatinina. Dos 30 cães que compuseram o G1, $30(100 \%)$ apresentaram evidenciação das paredes portais e da parede da vesícula biliar, 23 (76,67\%) fígado com dimensão preservada e bordos em ângulos agudos, 15 (50\%) faixa etária entre 1 e 6 anos de idade e $8(26,67 \%)$ eram da 
raça Lhasa apso. Não houve predisposição quanto ao sexo, assim como não foram identificadas alterações significativas nos exames bioquímicos e hematológicos dos cães do G1. Quanto aos diagnósticos clínicos atribuídos para estes cães, houve maior prevalência de gastroenterite (43,33\%). Dos 30 cães do G2, 27 animais (90\%) apresentaram hepatomegalia e arredondamento dos bordos hepáticos, 18 (60\%) tinham idade superior a 9 anos, $16(53,33 \%)$ eram fêmeas e 9 (30\%) eram da raça poodle. Houve elevação da atividade sérica de FA e elevação de ALT, redução nos níveis de proteínas séricas totais, albumina, globulinas, eritrócitos e volume globular, além de leucocitose por neutrofilia, com desvio à esquerda, eosinopenia, linfopenia e monocitose nos cães do G2. Neste grupo houve prevalência de doenças metabólicas (54\%), como diabetes mellitus e hiperadrenocorticismo, além das hepatopatias crônicas (17\%), atribuídas ao uso contínuo e prolongado de corticóide e drogas anticonvulsivantes. Dos 30 cães do grupo controle (G3), 22 $(73,33 \%)$ apresentaram dimensões hepáticas inalteradas e bordos em ângulos agudos. Neste grupo de animais, não houve alterações significativas nos exames laboratoriais.

TERMOS DE INDEXAÇÃO: Fígado, ultrassonografia, hematologia, bioquímica, caninos.

\section{INTRODUÇÃO}

As afecções hepáticas são frequentemente observadas na rotina veterinária, e em razão de seu comportamento clínico e bioquímico, na maioria das vezes, inespecíficos, exames de imagem, especialmente a ultrassonografia, são importantes métodos de diagnóstico e prognóstico para estas afecções. A ultrassonografia, ferramenta essencial para identificar anormalidades no parênquima hepático, trato biliar e sistema vascular (Cartee 1981, Lamb 1990, Biller et al. 1992, Barr 1995, Selcer 1995, Feeney et al. 2008), é capaz de acrescentar informações diagnósticas antes mesmo de serem observadas alterações em exames bioquímicos e em radiografias convencionais (Nyland et al. 1989, Mamprim et al. 1997, Kanemoto et al. 2013). Isso se deve ao fato de que $70 \%$ ou mais da capacidade funcional do fígado deve estar comprometida para que haja manifestações clínicas e alterações nas atividades séricas das enzimas hepáticas (Dial 1995, Tennant 1997).

As alterações focais e difusas de aspecto heterogêneo em parênquima hepático estão bem descritas na literatura veterinária, e são prontamente identificadas à ultrassonografia por causarem distorção significativa da região acometida (Partington \& Biller 1995). Todavia, é muito frequente, nos exames ultrassonográficos, a visibilização de alterações difusas da ecogenicidade hepática, as quais são mais difíceis de serem identificadas, especialmente as de padrão homogêneo, por não promoverem alteração evidente na arquitetura do parênquima hepático, e por requererem avaliação comparativa da ecogenicidade com outros órgãos abdominais, necessitando experiência e destreza do avaliador (Biller et al. 1992, Nyland et al. 2005). Na literatura veterinária há escassez de trabalhos científicos correlacionando alterações de ecogenicidade difusas e homogêneas do parênquima hepático aos seus respectivos achados laboratoriais e às afecções que acometem o fígado. Diante do exposto, objetivou-se, neste trabalho, analisar as alterações de ecogenicidade difusa do parênquima hepático homogêneo em cães em relação ao perfil dos animais, à dimensão hepática ao ultrassom e aos respectivos achados laboratoriais, bioquímicos e hematológicos. Os resultados encontrados poderão permitir à ultrassonografia um diagnóstico presuntivo, que, na ausência de exames laboratoriais específicos, fornecerá subsídios para o tratamento clínico e o possível prognóstico.

\section{MATERIAL E MÉTODOS}

Local. Os exames ultrassonográficos e a colheita das amostras de sangue foram realizadas no Hospital Veterinário Sena Madureira, São Paulo, Brasil. 0 processamento dessas amostras foi desenvolvido no Laboratório de Análises Clínicas CITOVET, Unidade Sena Madureira, São Paulo, Brasil.

Animais. Para a realização deste estudo foram selecionados 90 cães, machos e fêmeas, de diferentes pesos corpóreos, idades e raças variadas, que pela diversidade dos sinais clínicos foram submetidos à ultrassonografia abdominal como método de diagnóstico auxiliar. Condicional ao modelo experimental, os animais teriam que apresentar parênquima hepático com ecotextura homogênea e ecogenicidade considerada reduzida, aumentada ou normal, constituindo respectivamente os grupos G1, G2 e G3 (grupo controle), compostos por 30 cães cada um.

Exame ultrassonográfico. Os exames ultrassonográficos foram realizados em modo-B dinâmico, pelo mesmo profissional, em aparelho Aloka Echo Câmera (modelo SSD - 650), utilizando-se transdutores convexo de 5,0 $\mathrm{MHz}$ e linear de 7,5 MHz, empregados de acordo com o porte e a condição corpórea de cada animal. Para registro das imagens foi utilizada impressora da marca Sony Video Graphic Printer (modelo UP-897MD), com papel termal Sony (modelo UPP -110S). Como protocolo de exame foram empregadas as seguintes condições, os cães que se apresentavam em jejum alimentar por um período mínimo de 8 horas, os portadores de diabetes mellitus e os considerados de urgência foram avaliados prontamente, dispensando-se protocolo pré-determinado para a realização da ultrassonografia abdominal. Para os demais casos foi preconizado jejum alimentar de 24 horas e administração oral de dimeticona. Foi realizada tricotomia ampla do abdome ventral, de acordo com a metodologia descrita por Carvalho \& Iwasaki (2004). Não houve, para a realização da varredura eletrônica, a necessidade de contenção química. A técnica ultrassonográfica empregada foi a preconizada por Nyland et al. (2005) e o fígado considerado normal quando respeitava as características descritas na literatura (Barr 1992, Mamprim 2004, Nyland et al. 2005). Para se evitar artefatos técnicos, que poderiam ressaltar falsas alterações de ecogenicidade hepática, a análise comparativa do fígado com baço, rins e gordura falsiforme foi realizada utilizando-se imagens focadas na mesma profundidade de campo, como sugerem Biller et al. (1992).

Exames laboratoriais. Após o exame ultrassonográfico, todos os cães com estas características foram submetidos à colheita de sangue para análise laboratorial. Hemograma, dosagens das atividades séricas de alanina aminotransferase (ALT) e fosfatase alcalina (FA), concentrações de proteínas totais, albumina, globulinas, uréia e creatinina foram realizadas para todos os animais. Tabelas de referência foram utilizadas para os valores bioquímicos (Kaneko 1989, Bush 2004) e hematológicos (Shalm et al. 1975, Jain 1993). As amostras de sangue foram obtidas por punção venosa da jugular ou da cefálica do antebraço. As contagens globais de hemácias e leucócitos foram realizadas de 
imediato em contador eletrônico, com base no princípio da impedância em aparelho CELM modelo CC510, e a hemoglobina obtida por meio de hemoglobinômetro CELM, modelo HB520, pelo método de cianometahemoglobina. As plaquetas foram contadas em câmaras de Neubawer utilizando-se diluente de oxalato de amônia 1\% em água destilada. A análise morfológica das células sanguíneas, bem como a diferenciação celular e a conferência das contagens foram conduzidas por meio da observação de esfregaços sanguíneos corados com Giemsa, utilizando-se microscópio óptico Nikon FAhaphot YS2. As amostras de sangue sem EDTA foram centrifugadas à $800 \mathrm{~g}$ por 10 minutos, a fim de se obter $\mathrm{o}$ soro. A maioria das amostras foi processada durante a rotina, e quando isto não ocorreu, estas foram acondicionadas em epen$\operatorname{dorfs}$, identificadas e armazenadas em congelador a $-20^{\circ} \mathrm{C}$, até serem processadas, respeitando-se o prazo máximo de 48 horas da colheita até o processamento. As provas bioquímicas foram realizadas no aparelho Bioplus bio 200F, utilizando-se kits da marca Labtest e suas respectivas metodologias, como sugerem Willard \& Twedt (1994). Nos cães diabéticos a glicemia foi determinada prontamente, pelo método da glicose-oxidase, fazendo-se uso do aparelho Accu Chek Advantage com fitas específicas da mesma marca.

Análise estatística. Os dados referentes aos achados bioquímicos e hematológicos foram avaliados por meio de análise de variância pelo teste $\mathrm{F}$, para comparação entre grupos, e pelo teste de Tukey a $5 \%$ de probabilidade $(\mathrm{p}<0,05)$ para comparação das médias, de acordo com delineamento inteiramente casualizado. $\mathrm{Na}$ análise estatística deste modelo experimental observou-se que algumas variáveis bioquímicas e hematológicas apresentaram desvio padrão com valores superiores à média. Resultados estes, atribuídos a discrepância entre valores mínimos e máximos, de cada variável, decorrentes da heterogeneidade de cada grupo. Porém, este fato não prejudicou a análise comparativa entre grupos, uma vez que ocorreram diferenças significativas entres estes.

Para avaliar a correlação existente entre as variáveis bioquímicas e hematológicas em função de cada grupo, utilizou-se o coeficiente de correlação linear de Pearson, considerando $\mathrm{p}<0,05$. Os resultados foram submetidos ao programa Statistical Analysis System (SAS, 2002), Setor de Matemática Estatística da Faculdade de Ciências Agrárias e Veterinárias da Universidade Estadual Paulista (Unesp, Campus de Jaboticabal).

\section{RESULTADOS}

Nos cães que compuseram o G1 foram visibilizados em todos os animais que as paredes portais e a parede da vesícula biliar encontravam-se evidenciadas. A dimensão hepática estava preservada, com bordos de ângulos agudos, na maioria dos cães deste grupo (76,67\%). 0 padrão homogêneo e hipoecogênico do fígado ocorreu com maior frequência em cães com idade de 1-6 anos (50\%), sem predisposição sexual. A raça Lhasa Apso foi a mais acometida $(26,67 \%)$. Em dois animais, além do parênquima hipoecogênico, notou-se a vesícula biliar com paredes duplas. 0 quadro clínico destes dois animais cursava com a presença de icterícia. Em algumas amostras foi caracterizado o aumento discreto da atividade sérica das enzimas ALT e ALP, sem correlação entre estas pelo teste de Pearson ( $p>0,05)$. Assim como o aumento sérico de uréia e creatinina em pacientes renais, com correlação de Pearson positiva $(\mathrm{p}<0,05)$. Redução nos níveis de proteínas séricas totais e de albumina, com correlação positiva entre estas $(\mathrm{p}<0,05)$, foram detectadas em G1. Alterações no hemograma foram observadas em poucos cães, e quando presentes restritas a redução na contagem de eritrócitos e de volume globular, com correlação positiva entres estas $(\mathrm{p}<0,05)$. No caso de animais com desidratação houve elevação nos níveis destas duas variáveis. Além destes, notou-se leucocitose por neutrofilia, com desvio à esquerda e linfopenia em algumas amostras. Considerando os diferentes diagnósticos clínicos atribuídos para este grupo de animais (G1), a gastroenterite foi a afecção que apresentou a maior incidência $(43,33 \%)$, sendo a origem alimentar preponderante $(84,62 \%)$. Estes dados estão ilustrados nas Figuras 1, 3, 4 e 5, e discriminados nos Quadros 1 a 9.

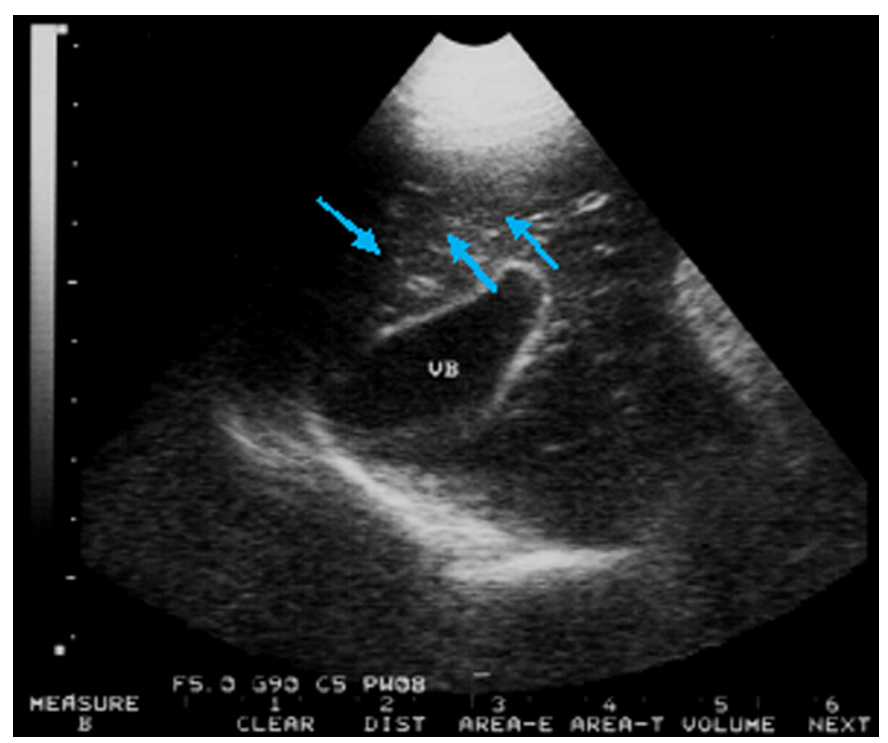

Fig.1. Imagem ultrassonográfica do parênquima hepático, em plano transversal, de um cão da raça Lhasa apso, macho, 3 anos de idade, com quadro clínico de gastroenterite de origem alimentar. Notar a redução difusa de ecogenicidade hepática, com evidenciação dos ramos portais (setas).

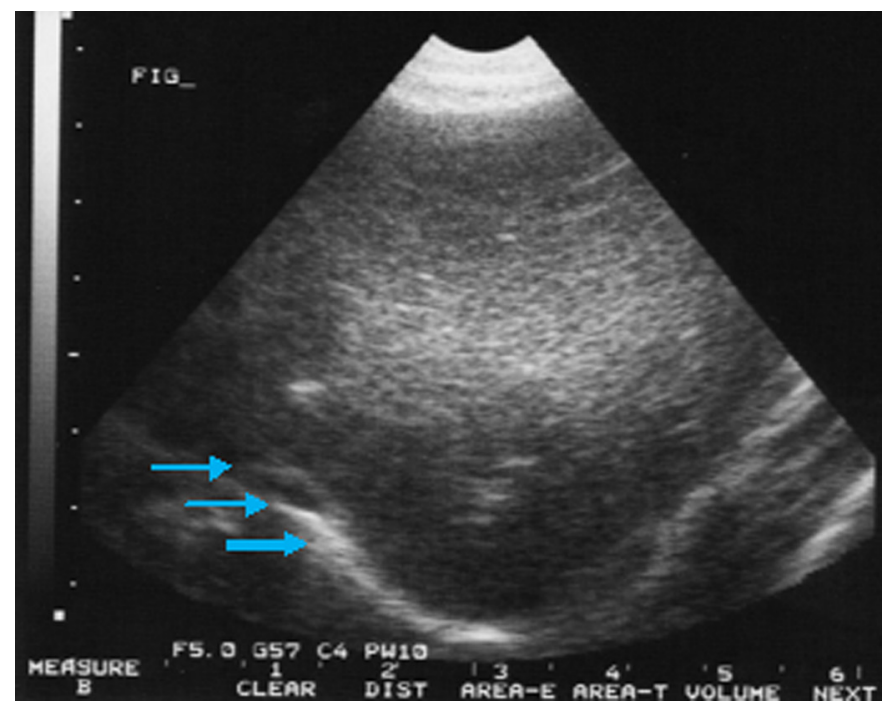

Fig.2. Imagem ultrassonográfica do parênquima hepático, em plano transversal, de um cão da raça teckel, fêmea, 14 anos de idade, com diabetes mellitus. Notar o aumento de ecogenicidade difusa do parênquima hepático, acompanhado por atenuação posterior do feixe sonoro (setas). 


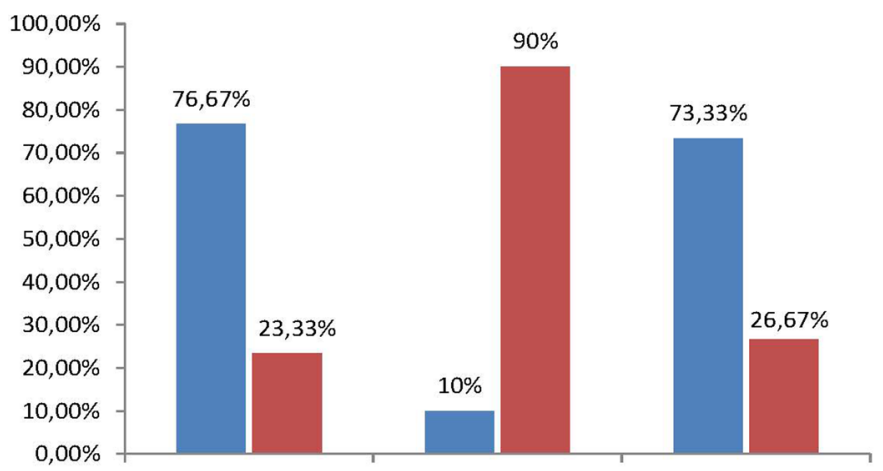

Fig.3. Porcentagem dos eventos relacionados à dimensão hepática considerada normal ou aumentada em cães com ecogenicidade hepática reduzida (G1), aumentada (G2) e normal (G3).

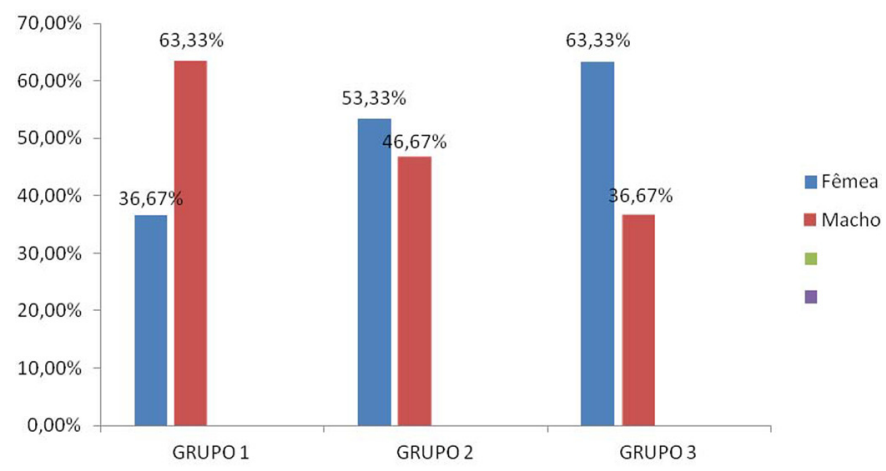

Fig.4. Distribuição dos cães por faixa etária em função da ecogenicidade hepática reduzida (G1), aumentada (G2) e normal (G3).

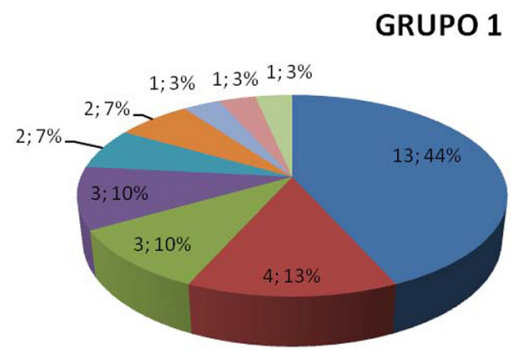

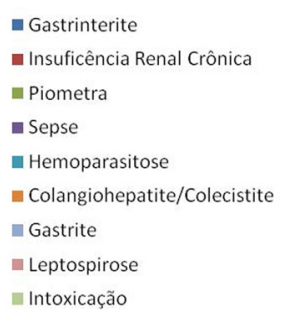

Fig.5. Frequência e porcentagem dos eventos observados nos cães com ecogenicidade hepática reduzida (G1).

Nos cães que compuseram o G2 visibilizou-se alta incidência de hepatomegalia e arredondamento dos bordos hepáticos (90\%). O padrão homogêneo e hiperecogênico ocorreu com maior frequência em cães idosos, com idade superior a 9 anos (60\%). As fêmeas (53,33\%) e os cães da raça Poodle (30\%) foram os mais acometidos. Aumento da atividade sérica de ALP (até 3.968U/L) e elevação de ALT, com correlação positiva entre estas pelo teste de Pearson $(\mathrm{p}<0,05)$, foi frequente. Em algumas amostras ocorreu redução nos níveis de proteínas séricas totais, albumina, globulinas, eritrócitos e volume globular, com correlação positiva entre estas variáveis pelo teste de Pearson $(\mathrm{p}<0,05)$. Leucocitose por neutrofilia, com desvio à esquerda, eosinopenia, linfopenia e monocitose também foram observadas. Houve aumento de uréia e creatinina em algumas amostras,

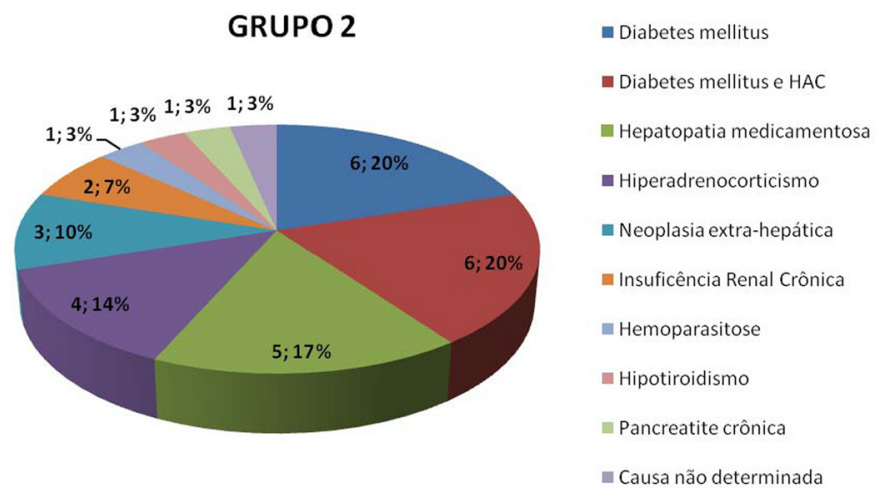

Fig.6. Frequência e porcentagem dos eventos observados nos cães com ecogenicidade hepática aumentada (G2).

\section{Grupo 3}

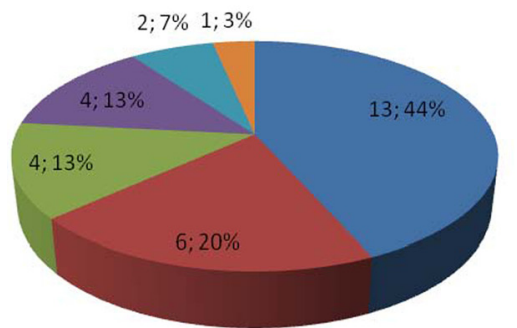

Monitoramento terapêutico
- Avaliação pré-operatória
- Atropelamento
- Gastrite
- Avaliaçãogeral
- Suspeita de Metástase

Fig.7. Frequência e porcentagem dos eventos observados nos cães com ecogenicidade hepática considerada normal (G3), após a varredura eletrônica da cavidade abdominal.

com correlação positiva entre estas $(\mathrm{p}<0,05)$. Neste grupo, dos quadros clínicos apresentados, os mais observados foram as doenças metabólicas, como diabetes mellitus e hiperadrenocorticismo, e as hepatopatias crônicas, atribuídas ao uso contínuo e prolongado de corticóide e drogas anticonvulsivantes. Nos cães com diabetes mellitus e hiperadrenocorticismo, a atenuação do feixe sonoro foi evidenciada à varredura hepática Estes dados estão ilustrados nas Figuras 2, 3, 4 e 6, e discriminados nos Quadros 1 a 9.

Nos cães que compuseram o G3, caracterizados e selecionados por apresentarem parênquima hepático homogêneo e ecogenicidade normal, observou-se o fígado com dimensões inalteradas, dentro do gradil costal, e com os bordos de ângulos agudos em 73,33\% dos animais. Neste grupo controle não ficou caracterizada alterações laboratoriais significativas, todavia ocorreu o aumento de ALT

Quadro 1. Médias, desvios-padrão, valores mínimos e máximos obtidos para alanina aminotransferase (ALT - U/L) e fosfatase alcalina (ALP - U/L) em cães com ecogenicidade hepática reduzida (G1), aumentada (G2) e normal (G3), submetidos ao teste de Tukey a $5 \%$ e ao teste $F$

\begin{tabular}{ccccc}
\hline GRUPO & ALT & $\begin{array}{c}\text { Valor Mínimo } \\
\text { e Máximo }\end{array}$ & ALP & $\begin{array}{c}\text { Valor Mínimo } \\
\text { e Máximo }\end{array}$ \\
\hline 1 & $128 \pm 184 \mathrm{ab}$ & $15,2-768$ & $209 \pm 270 \mathrm{~b}$ & $35,7-1.448$ \\
2 & $182 \pm 181 \mathrm{a}$ & $32,1-700$ & $985 \pm 1020 \mathrm{a}$ & $64,7-3.968$ \\
3 & $53,8 \pm 17,4 \mathrm{~b}$ & $22,7-95,80$ & $88,7 \pm 64,1 \mathrm{~b}$ & $13,8-348$ \\
Teste F & 5,58 & - & 19,05 & - \\
P & 0,0053 & - & 0,0001 & -
\end{tabular}


Quadro 2. Médias, desvios-padrão e valores mínimos e máximos obtidos para proteína sérica total $(\mathrm{g} / \mathrm{dL})$ em cães com ecogenicidade hepática reduzida (G1), aumentada (G2) e normal (G3), submetidos ao teste de Tukey a $5 \%$ e ao teste $F$

\begin{tabular}{ccc}
\hline GRUPO & Proteínas totais & Valor Mínimo e Máximo \\
\hline 1 & $6,12 \pm 1,17 \mathrm{a}$ & $3,5-7,60$ \\
2 & $6,83 \pm 1,78 \mathrm{a}$ & $4,1-13,41$ \\
3 & $6,32 \pm 0,85 \mathrm{a}$ & $4,9-8,70$ \\
Teste F & 2,33 & - \\
P & 0,1037 & -
\end{tabular}

Quadro 3. Médias, desvios-padrão, valores mínimos e máximos obtidos para dosagem sérica de albumina $(\mathrm{g} / \mathrm{dL})$ e de globulinas (g/dL) em cães com ecogenicidade hepática reduzida (G1), aumentada (G2) e normal (G3), submetidos ao teste de Tukey a $5 \%$ e ao teste $F$

\begin{tabular}{ccccc}
\hline GRUPO & Albumina & $\begin{array}{c}\text { Mínimo e } \\
\text { Máximo }\end{array}$ & Globulinas & $\begin{array}{c}\text { Mínimo e } \\
\text { Máximo }\end{array}$ \\
\hline 1 & $2,55 \pm 0,58 \mathrm{~b}$ & $1,00-3,74$ & $3,57 \pm 0,92 \mathrm{ab}$ & $2,14-5,29$ \\
2 & $2,76 \pm 0,69 \mathrm{ab}$ & $1,53-4,80$ & $4,07 \pm 1,28 \mathrm{a}$ & $2,12-8,61$ \\
3 & $2,91 \pm 0,45 \mathrm{a}$ & $2,10-3,84$ & $3,41 \pm 0,78 \mathrm{~b}$ & $1,38-5,29$ \\
Teste F & 2,92 & - & 3,46 & - \\
P & 0,0493 & - & 0,0357 & -
\end{tabular}

Quadro 4. Médias, desvios-padrão e valores mínimos e máximos obtidos para uréia e creatinina em cães com ecogenicidade hepática reduzida (G1), aumentada (G2) e normal (G3), submetidos ao teste de Tukey a 5\% e ao teste F

\begin{tabular}{ccccc}
\hline GRUPO & Uréia & Mínimo e Máximo & Creatinina & Mínimo e Máximo \\
\hline 1 & $72,1 \pm 103$ a & 13,5562 & $1,81 \pm 1,41$ a & $0,42-7,1$ \\
2 & $68,6 \pm 77,7$ a & $12,2-400$ & $1,39 \pm 0,86$ a & $0,40-4,7$ \\
3 & $40,9 \pm 37,0$ a & $13,8-204$ & $1,31 \pm 0,58$ a & $0,50-3,4$ \\
Teste F & 1,46 & - & 2,13 & - \\
P & 0,2388 & - & 0,1247 & -
\end{tabular}

Quadro 5. Médias, desvios-padrão e valores mínimos e máximos obtidos para contagens globais de eritrócitos $(\mathrm{x} 106 / \mu \mathrm{L})$ e volume globular (\%) em cães com ecogenicidade hepática reduzida (G1), aumentada (G2) e normal (G3), submetidos ao teste de Tukey a $5 \%$ e ao teste $F$

\begin{tabular}{ccccc}
\hline GRUPO & Eritrócitos & $\begin{array}{c}\text { Mínimo e } \\
\text { Máximo }\end{array}$ & $\begin{array}{c}\text { Volume } \\
\text { globular }\end{array}$ & $\begin{array}{c}\text { Mínimo e } \\
\text { Máximo }\end{array}$ \\
\hline 1 & $6,59 \pm 1,33 \mathrm{a}$ & $4,0-10,00$ & $48,3 \pm 9,55 \mathrm{a}$ & $27-74$ \\
2 & $5,73 \pm 1,66 \mathrm{~b}$ & $1,9-7,9$ & $40,4 \pm 10,9 \mathrm{~b}$ & $16-57$ \\
3 & $6,79 \pm 0,93 \mathrm{a}$ & $5,1-8,9$ & $47,9 \pm 6,3 \mathrm{a}$ & $36-60$ \\
Teste F & 5,26 & - & 7,07 & - \\
P & 0,0070 & - & 0,0014 & -
\end{tabular}

Quadro 6. Médias, desvios-padrão, valores mínimos e máximos obtidos para contagens globais de leucócitos $(\mathrm{x} 103 / \mu \mathrm{L})$ em cães com ecogenicidade hepática reduzida (G1), aumentada (G2) e normal (G3), submetidos ao teste de Tukey a $5 \%$ e ao teste $F$

\begin{tabular}{ccc}
\hline GRUPO & Leucócitos totais & Valor Mínimo e Máximo \\
\hline 1 & $15.549 \pm 6.600 \mathrm{a}$ & $6.500-33.000$ \\
2 & $16.453 \pm 8.601 \mathrm{a}$ & $5.300-40.000$ \\
3 & $11.416 \pm 3.965 \mathrm{~b}$ & $5.700-23.100$ \\
Teste F & 4,87 & - \\
P & 0,0099 & -
\end{tabular}

em um cão e de ALP em dois outros cães. No hemograma, observou-se em dois outros animais o aumento na contagem de eritrócitos e volume globular, o que foi sugestivo da presença de desidratação. Estes dados estão ilustrados nas Figuras 3, 4 e 7, e discriminados nos Quadros 1 a 9.

Quadro 7. Médias, desvios-padrão, valores mínimos e máximos obtidos para contagem absoluta de bastonetes

$(/ \mu \mathrm{L})$ e neutrófilos segmentados $(/ \mu \mathrm{L})$ em cães com ecogenicidade hepática reduzida (G1), aumentada (G2) e normal (G3), submetidos ao teste de Tukey a $5 \%$ e ao teste $F$

\begin{tabular}{ccccc}
\hline GRUPO & Bastonetes & $\begin{array}{c}\text { Mínimo e } \\
\text { Máximo }\end{array}$ & Segmentados & $\begin{array}{c}\text { Mínimo e } \\
\text { Máximo }\end{array}$ \\
\hline 1 & $491 \pm 852 \mathrm{a}$ & $0-2508$ & $12.772 \pm 6.297 \mathrm{a}$ & $4.469-29.700$ \\
2 & $258 \pm 620 \mathrm{ab}$ & $0-2652$ & $13.641 \pm 7.147 \mathrm{a}$ & $3.710-30.959$ \\
3 & $9,8 \pm 53,6 \mathrm{~b}$ & $0-294$ & $8.553 \pm 3.515 \mathrm{~b}$ & $3.705-22.176$ \\
Teste F & 4,68 & - & 5,07 & - \\
P & 0,0117 & - & 0,0083 & -
\end{tabular}

Quadro 8. Médias, desvios-padrão e valores mínimos e máximos obtidos para a contagem absoluta de eosinófilos e linfócitos típicos $(/ \mu \mathrm{L})$ em cães com ecogenicidade hepática reduzida (G1), aumentada (G2) e normal (G3), submetidos ao teste de Tukey a $5 \%$ e ao teste $F$

\begin{tabular}{ccccc}
\hline GRUPO & Eosinófilos & $\begin{array}{c}\text { Valor Mínimo e } \\
\text { Máximo }\end{array}$ & Linfócitos Tip. & $\begin{array}{c}\text { Valor Mínimo e } \\
\text { Máximo }\end{array}$ \\
\hline 1 & $199 \pm 372 \mathrm{a}$ & $0-1.830$ & $1.342 \pm 1.280 \mathrm{a}$ & $302-5.886$ \\
2 & $162 \pm 313 \mathrm{a}$ & $0-1.600$ & $1.159 \pm 707 \mathrm{a}$ & $110-2.650$ \\
3 & $351 \pm 319 \mathrm{a}$ & $0-946$ & $1.631 \pm 1.033 \mathrm{a}$ & $114-3.700$ \\
Teste F & 2,67 & - & 1,59 & - \\
P & 0,0752 & - & 0,2099 & -
\end{tabular}

Quadro 9. Médias, desvios-padrão, valores mínimos e máximos obtidos para contagem absoluta de monócitos $(/ \mu \mathrm{L})$ em cães com ecogenicidade hepática reduzida (G1), aumentada (G2) e normal (G3), submetidos ao teste de Tukey a $5 \%$ e ao teste F

\begin{tabular}{lcc}
\hline GRUPO & Monócito & Valor Mínimo e Máximo \\
\hline 1 & $811 \pm 640 \mathrm{ab}$ & $86-3.487$ \\
2 & $1.211 \pm 1.170 \mathrm{a}$ & $66-5.968$ \\
3 & $531 \pm 295 \mathrm{~b}$ & $82-1.120$ \\
Teste F & 5,64 & - \\
P & 0,0050 & -
\end{tabular}

\section{DISCUSSÃO E CONCLUSÃO}

Notou-se a precocidade da ultrassonografia na detecção de alterações em parênquima hepático, mesmo na ausência de mudanças em exames bioquímicos, concordando com relatos descritos por Nyland et al. (1989) e Mamprim et al. (1997). Desta forma, pode-se reafirmar que a ultrassonografia é uma ferramenta essencial para identificar anormalidades no parênquima hepático e trato biliar (Cartee 1981, Lamb 1990, Biller, et al. 1992, Barr 1995, Selcer 1995, Feeney et al. 2008). No entanto, não é específica para determinar a etiologia das enfermidades (Konde et al. 2005, Feeney et al. 2008, Kemp et al. 2013), o que torna necessário a realização de métodos como citologia com agulha fina e biópsia hepática para obtenção do diagnóstico definitivo (Santilli \& Biller 1993, Stockhaus et al. 2004, Nyland et al. 2005). Neste projeto levou-se em consideração o aspecto real da rotina veterinária em hospitais particulares, onde o 
proprietário, em detrimento do caráter invasivo, raramente permite a prática desses procedimentos. Esta informação enfatiza a importância da interpretação dos exames laboratoriais de rotina em associação aos achados ultrassonográficos hepáticos.

Nos cães que compuseram o G1, as alterações ultrassonográficas referentes aos ramos portais evidentes e a dimensão hepática preservada, foram também descritas por Barr (1995), Mamprim (2004) e Konde et al. (2005). A maior frequência de cães entre 1 e 6 anos, apresentando este tipo de padrão ultrassonográfico (G1), pode ser explicada pela prevalência de enfermidades agudas, uma vez que o caráter crônico destas tende a ser observado em animais idosos, como ocorreu nos cães do G2. A maior incidência em cães com raça definida, destacando a raça Lhasa Apso, não requer relevância, por se tratar de amostra viciada em detrimento do elevado poder aquisitivo dos proprietários e clientes do local onde foi desenvolvido este trabalho. Há evidências que o fígado esteja sujeito a infecções por várias vias, incluindo a hematógena (portal ou arterial) e a ascendente (via trato biliar), que podem causar lesão hepática primária (hepatopatia tóxica) ou incitar reações imunológicas que levam ao desenvolvimento do processo inflamatório (Cullen \& Maclachlan 2001, Ritcher 2005). Sendo assim, o padrão ultrassonográfico hipoecogênico visibilizado nos animais deste grupo pôde ocorrer pelo acúmulo de líquido em hepátocitos, desencadeado pelo provável processo inflamatório envolvido (Mamprim 2004). A presença de edema na parede da vesícula biliar, visibilizado concomitantemente à redução de ecogenicidade hepática em dois cães do G1, pode indicar lesão hepática primária, traduzindo um processo inflamatório tanto hepático como biliar (Mamprim 2004). Nestes casos, houve redução acentuada da ecogenicidade hepática, possivelmente pela severidade da lesão em hepatócitos, a qual poderia ser confirmada por meio do exame histológico, não permitido na ocasião. Quanto aos testes bioquímicos, os resultados foram típicos de lesão hepatocelular moderada a severa, com alta atividade sérica de ALT (até 715 U/L) e variável aumento da atividade sérica de ALP (até $361 \mathrm{U} / \mathrm{L}$ ), resultados condizentes com Willard \& Twedt (1994). Nos outros cães do G1, o discreto aumento das atividades séricas das enzimas ALT e ALP pode ser explicado pelo menor dano hepatobiliar. Acrescenta-se que este aumento foi observado somente em cães com período de convalescência prolongado, sugerindo que a elevação destas enzimas possa ter ocorrido em detrimento do maior tempo de permanência do agente causal ou por colestase, em decorrência do jejum alimentar prolongado. Três outros cães deste mesmo grupo de animais (G1), acometidos por afecções agravadas pela presença de sepse (decorrente de abscesso supurado no pólo caudal do rim esquerdo, uroperitônio e endocardite), apresentaram elevação unicamente da atividade sérica de ALP. Há evidências de que a endotoxina bacteriana interage com o sistema de secreção biliar, impedindo a secreção de bile sem relevante dano hepatocelular (Nelson \& Couto 2006). As poucas alterações encontradas no hemograma do G1, relativas à redução da contagem de eritrócitos e de volume globular, ocorreram, provavelmente, em razão do fenômeno mór- bido envolvido (Dial 1995). Em contrapartida, o aumento destas variáveis pode ter ocorrido em consequência da desidratação associada a algumas afecções observadas, como nas gastroenterites. Destruição ou perda protéica intestinal ou glomerular podem ter sido responsáveis pela redução dos níveis de proteínas séricas totais e de albumina (Bush 2004). A leucocitose por neutrofilia, com desvio à esquerda, e linfopenia notadas nos cães do G1 são condizentes com as citações de Meyer et al. (1995) e Nelson \& Couto (2006). Em algumas amostras notou-se neutrófilos tóxicos associados ao desvio à esquerda, o que sugere leucocitose na presença de processo infeccioso (Bush 2004). 0 aumento dos níveis séricos de uréia e creatinina em alguns cães do G1, pode sugerir o comprometimento de $75 \%$ ou mais da capacidade funcional dos néfrons, como referido por Lanis et al. (2008). Coincidentemente estes achados laboratoriais implicaram na perda das definições córtico-medulares e aumento de ecogenicidade das corticais destes cães. Vale ressaltar que a função renal não pode ser diretamente relacionada ao aspecto ultrassonográfico, uma vez que as lesões anatômicas nem sempre estão relacionadas às alterações funcionais (Green 1996).

A hepatomegalia presente na maioria dos cães do G2 (90\%) condiz com os achados de Biller et al. (1992) e Machado et al. (2002). De acordo com Ritcher (2005), os principais eventos que levam à hepatomegalia são o aumento na concentração de corticóide (exógenos ou endógenos), acúmulo de gordura (esteatose) e inflamação difusa, apontados com frequência nos cães do G2. A atenuação do feixe sonoro, presente nos casos de esteatose, ocorre pela dificuldade do som em transpor o parênquima hepático, em razão da infiltração de gordura nos hepatócitos. Este aspecto foi frequentemente relacionado com diabetes mellitus, concordando com Marchesini et al. (2003) e Mamprim (2004). Syakalima et al. (1998) relataram a presença de atenuação do feixe sonoro associada à hepatopatia esteroidal. Todavia, esta relação não foi estabelecida neste modelo experimental, fazendo-se necessário estudo mais aprofundado. A maior frequência de cães com idade superior a nove anos no G2 advém da ocorrência de distúrbios crônicos e metabólicos, que geralmente acometem os pacientes idosos (Silva 2007). As fêmeas foram mais acometidas, o que reforça a interação entre os hormônios sexuais e o metabolismo da glicose (Guptill et al. 2003). Houve prevalência da raça poodle, o que confirma a predisposição destes animais a doenças metabólicas (Hess et al. 2000). Na literatura veterinária compilada, há citação do uso de fármacos, como anticonvulsivantes (fenitoína, primidona e fenobarbital) gerando disfunção hepática (Chauvet et al. 1995, Müller et al. 2000, Aitken et al. 2003). Entretanto, não existem relatos associando essas disfunções com suas respectivas aparências ultrassonográficas. Neste trabalho foi possível estabelecer relação entre estas variáveis, onde foi visibilizado aumento de ecogenicidade difusa do parênquima hepático, acompanhado de hepatomegalia e arredondamento dos bordos hepáticos, com aumento concomitante da atividade sérica das enzimas ALT e ALP. É provável que o acréscimo da atividade sérica da enzima ALP, identificado nos pacientes com hepatopatia esteroidal, seja inerente ao aumento 
da atividade sérica da forma homóloga da isoenzima corticóide-induzida, ou ainda pela hepatopatia provocada por esta medicação (Meyer et al. 1995). A correlação positiva entre o aumento da atividade das enzimas ALT e ALP pode ser causada por danos hepatocelulares, oriundos do acometimento crônico do parênquima hepático (Meyer et al. 1995). As doenças hepáticas crônicas dos cães do G2 levam a redução dos eritrócitos e por sua vez do volume globular, em razão da supressão da eritrogênese (Dial 1995). Estes dados estão relacionados também com o decréscimo das proteínas totais, albumina e globulinas pelo déficit da síntese protéica em razão da hepatopatia crônica (Maddison 1990). A leucocitose por neutrofilia com desvio à esquerda, eosinopenia, linfopenia e monocitose, identificadas nos cães do G2, pode ocorrer por liberação de corticóide endógeno, desencadeada por estresse ou por hepatopatia esteroidal (Meyer et al. 1995, Nelson \& Couto 2006).

Os cães do grupo controle (G3), como prejulgado ao ultrassom, não apresentaram alterações significativas dos parâmetros laboratoriais analisados. Contudo, em amostras de dois cães notou-se a elevação da atividade sérica das enzimas ALT e ALP, e na contagem de eritrócitos e volume globular, quadro que permite afirmar que o parênquima hepático com ecogenicidade e ecotextura normal não exclui a presença de alterações bioquímicas e hematológicas.

Mais estudos descritivos sobre as alterações difusas e homogêneas do parênquima hepático, especialmente com a realização de exame histotológico, são necessários e de grande valia para a orientação diagnóstica e terapêutica das hepatopatias em cães.

\section{REFERÊNCIAS}

Aitken M.M., Hall E., Scott L., Davot J.L. \& Allen W.M. 2003. Liver-relates biochemical changes in the serum of dogs being treated with phenobarbitone. Vet. Rec. 153:13-16.

Barr F.J. 1992. Ultrasonographic assesment of liver size in the dog. J. Small Anim. Pract. 31: 359-364.

Barr F.J. 1995. Percutaneus biopsy of abdominal organs ultrasound guidance. J. Small Anim. Pract. 36:105-113.

Biller D.S., Kantrowitz B. \& Miyabayashi T. 1992. Ultrasonography of diffuse liver disease. J. Vet. Intern. Med. 6:71-76.

Bush B.M. 2004. Interpretação de Resultados Laboratoriais para Clínicos de Pequenos Animais. Roca, São Paulo. 384p.

Cartee R.E. 1981. Diagnostic real time ultrasonography os the liver of the dog and cat. J. Am. Anim. Hosp. Assoc. 17:731-737.

Carvalho C.F. \& Iwasaki M. 2004. Ultra-sonografia abdominal em cães: contribuição ao estudo das técnicas de varredura de fígado, vesícula biliar, baço e rins. Clínica Veterinária 51:58-70.

Chauvet A.E., Feldman E.C. \& Kass P.H. 1995. Effects of Phenobarbital administration on results of serum biochemical analyses and adrenocortical function tests in epileptic dogs. J. Am. Vet. Med. Assoc. 207:1305-1307.

Cullen J.M. \& MacLachlan N.J. 2001. Liver, biliary system, and exocrine pancreas, p.81-124. In: McGavin M.D., Carlton W.W. \& Zachary J.F. (Eds), Special Veterinary Pathology. $3^{\text {rd }}$ ed. Mosby, Missouri. 768p.

Dial S.M. 1995. Clinicopathologic evaluation of the liver. Vet. Clin. North Am., Small Anim. Pract. 25:257-273.

Feeney D.A., Anderson K.L., Ziegler L.E., Jessen C.R., Daubs B.M. \& Hardy R.M. 2008. Statistical relevance of ultrasonographic criteria in the assessment of diffuse liver disease in dogs and cats. Am. J. Vet. Res. 69:212221.
Green R.W. 1996. Kidneys, p.197-210. In: Ibid. (Ed.), Small Animal Ultrasound. Lippincott Williams and Wilkins, Philadelphia, 377p.

Guptill L., Glickman L. \& Glickman N. 2003. Time trends and risk factors for diabetes mellitus in dogs: analysis of veterinary medical data base records. Vet. Journal, 165:240-247.

Hess R.S., Kass P.H. \& Ward C.R. 2000. Breed distribution of dogs with diabetes mellitus admitted to a tertiary care facility. J. Am. Vet. Med. Assoc. 216:1414-1417.

Jain N.C. 1993. Essentials of Veterinary Hematology. Lea and Febiger, Philadelphia. 417p.

Kaneko J.J. 1989. Clinical Biochemistry of Domestic Animals. $4^{\text {th }}$ ed. Academic Press, Missouri. 932p.

Kanemoto H., Sakai M., Sakamoto Y., Spee B., Van den Ingh T.S., Schotanus B.A., Ohno K. \& Rothuizen J. 2013. American Cocker Spaniel chronic hepatitis in Japan. J. Vet. Intern. Med. 27:1041-1048.

Kemp S.D., Panciera D.L., Larson M.M., Saunders G.K. \& Werre S.R. 2013. A comparison of hepatic sonographic features and histopathologic diagnosis in canine liver disease: 138 cases. J. Vet. Intern. 27:806-813.

Konde L.J., Green P.A. \& Pugh C.R. 2005. Radiologia e ultra-sonografia do sistema digestório, p.67-91. In: Tams T.D. (Ed.), Gastroenterologia de Pequenos Animais. $2^{\mathrm{a}}$ ed. Roca, São Paulo. 472p.

Lamb C.R. 1990. Abdominal ultrasonography in small animals: Examination of liver, spleen and pancreas. J. Small Anim. Pract. 31:5-14.

Lanis A.B., Fonseca L.A., Roesler T., Alves A. \& Lopes B. 2008. Avaliação laboratorial das doenças renais em pequenos animais. Pubvet. 28: sem número de páginas (artigo científico publicado em periódico eletrônico) - Disponível em: http://www.pubvet.com.br/artigos_det.asp?artigo=29

Machado M.M., Rosa A.C.F. \& Cerri G.G. 2002. Doenças hepáticas difusas, hipertensão portal e transplante de fígado, p.55-123. In: Cerri G.G. \& Oliveira I.R.S. (Eds), Ultra-sonografia Abdominal. Revinter, Rio de Janeiro. 618 .

Maddison J.E. 1990. The diagnostic approach to hepatic disease in the dog. Aust. Vet J. 20:2-7.

Mamprim M.J., Rocha N.S., Muniz L.M.R., Vulcano L.C. \& Leal A.C.R. 1997. Imagem ultra-sonográfica de metástase abdominal de tumor venéreo transmissível: relato de caso. Anais XIX Congresso Brasileiro de Clínicos Veterinários de Pequenos Animais, Curitiba, PR, p.44.

Mamprim M.J. 2004. Fígado e vesícula biliar, p.5-73. In: Carvalho C.F. (Ed.), Ultra-sonografia em Pequenos Animais. Roca, São Paulo. 365p.

Marchesini G., Bugianesi E., Forlani G., Cerrelli F., Lenzi M., Manini R., Natale S., Vanni E., Villanova N., Melchionda N. \& Rizzetto M. 2003. Nonalcoholic fatty liver, steatohepatitis, and the metabolic syndrome. Hepatology 37:917-923.

Meyer D.J., Coles E.H. \& Rich L.J. 1995. Anormalidades em testes hepáticos, p.47-61. In: Ibid. (Eds), Medicina de Laboratório Veterinária: interpretação e diagnóstico. Roca, São Paulo. 308p.

Müller P.B., Taboada J., Hosgood G., Partington B.P., Vansteenhouse J.L., Taylor H.W. \& Wolfsheimer K.J. 2000. Effects of long-term phenobarbital treatment on the liver in dogs. J. Vet. Intern. Med. 14:165-171.

Nelson R.W. \& Couto C.G. 2006. Testes diagnósticos para o sistema hepatobiliar, p.467-80. In: Ibid. (Eds), Medicina Interna de Pequenos Animais. $3^{\underline{a}}$ ed. Mosby Elsevier, Rio de Janeiro. 1324p.

Nyland T.G., Hager D.A \& Herring D.S. 1989. Sonography of liver, gallbladder and spleen. Semin Vet. Med. Surg. 4:13-31.

Nyland T.G., Matton J.S. \& Herrgesell E.J. 2005. Fígado, p.95-130. In: Nyland T.G. \& Matton J.S. (Eds), Ultra-som Diagnóstico em Pequenos Animais. Roca, São Paulo. 469p.

Partington B.P. \& Biller D.S. 1995. Hepatic imaging with radiology and ultrasound. Vet. Clin. North Am., Small Anim. Pract. 25:305-335.

Ritcher K.P. 2005. Doenças do fígado e do sistema hepatobiliar, p.283-348. In: Tams T.D. (Ed.), Gastroenterologia de Pequenos Animais. $2^{\underline{a}}$ ed. Roca, São Paulo. 472p.

Santilli R.A. \& Biller D.S. 1993. Ultrasonography of the liver and biliary tract. Veterinaria 3:19-26. 
SAS 2002. Statistical Analysis System. Institute Inc., Cary, North Carolina, USA.

Selcer B.A. 1995. The liver and gallbladder, p.88-105. In: Cartee R.E. (Ed.), Practical Veterinary Ultrasound. Williams and Wilkins, Baltimore. 329p.

Shalm O.W., Jain N.C. \& Carroll E.J. 1975. Veterinary Hematology. Lea and Febiger, Philadelphia, 470p.

Silva M.C. 2007. Cirrose hepática em cães: 80 casos (1965-2003). Pesq. Vet. Bras. 27:71-80.

Syakalima M., Takiguchi M., Yasuda J., Morita Y. \& Hashimoto A. 1998. Comparison of attenuation and liver kidney contrast of liver ultraso- nographs with histology and biochemistry in dogs with experimentally induced steroid hepatopathy. Vet. Quaterly 20:18-22.

Stockhaus C., Ingh T.V.D., Rothuizen J. \& Teske E. 2004. A multistep approach in the cytologic evaluation of liver biopsy samples of dogs with hepatic diseases. Vet. Pathol. 41:461-470.

Tennant B.C. 1997. Hepatic function, p.327-352. In: Kaneko J.J., Harvey J.W. \& Bruss M.L. (Eds), Clinical Biochemistry of Domestic Animals. Academic Press, San Diego. 932p.

Willard M.D. \& Twedt D.C. 1994. Gastrointestinal, pancreatic and hepatic disorders, p. 179-218. In: Ibid. (Eds), Small Animal Diagnosis by Laboratory Methods. $2^{\text {nd }}$ ed. W.B. Saunders, Philadelphia. 377p. 